\title{
TYPING for COLLEGES
}

for elementary and intermediate examinations

\section{Paul Bailey BA, FRSA, FSCT}

\section{Edited by}

Susan Hartley FSCT

\section{Second Edition}

All rights reserved. No part of this publication may be reproduced or transmitted, in any form or by any means, without permission.

\section{First edition 1973}

Second edition 1977

\section{Published by}

THE MACMILLAN PRESS LTD

London and Basingstoke

Associated companies in Delhi Dublin

Hong Kong Johannesburg Lagos Melbourne

New York Singapore and Tokyo

ISBN 978-1-349-81495-4

ISBN 978-1-349-81493-0 (eBook)

DOI 10.1007/978-1-349-81493-0

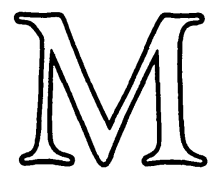




\section{Preface}

Typing for Colleges is a basic textbook which covers the syllabuses of the elementary level examinations of the public examining bodies and covers most of the intermediate level syllabuses. It has been rewritten with the latest examination syllabuses in mind and lecturers and students in colleges in particular will welcome its distinctive features.

* It is lesson-planned. The lessons provide a planned sequence of work in which new techniques and theory are introduced, practised, applied and consolidated, while at the same time pure typing skill is maintained and developed. The explanations are given in step-by-step form and are simpler and more detailed than is usual, for example, in dealing with tabulations.

* The carefully-graded teaching system encourages confidence and self-reliance in the students and enables them to set out work rather than merely copy correct examples all the time.

* It contains a high proportion of manuscript exercises, which are introduced early in the course.

* It contains a large section on business documents and forms of various kinds.

* It contains metric symbols as well as fractions, combination signs and printers' corrections signs, etc.

* It contains foreign languages.

* Many of the exercises are linked.

* It presents a simple non-calculation method of vertical and horizontal display.

* Although the book necessarily adopts a particular style in any example, where there are alternative styles which are acceptable, these are mentioned. A page is devoted to the marking of examination papers.

* There are a number of Quick Tests which test theory in a practical manner.

* Target times are given for all production work. These are based on the times taken by many groups of students of all ages.

* It contains a large number of skill-building exercises ranging in difficulty from syllabic intensity (SI) 1.00 to SI 1.48 .

There are 72 Increase Speed passages, starting at 15 wpm for 1 minute at SI 1.00 and continuing to 40 wpm for 5 minutes at SI 1.06 . There are 76 Improve Accuracy passages - most of which teach some commercial topic - starting at 15 wpm for 1 minute at SI 1.26 and continuing to 40 wpm for 5 minutes at SI 1.25 .

There are 33 Test your Skill passages, starting with 26 words at SI-1.15 and continuing to 479 words at SI 1.18 ; timings are from 1 to 10 minutes.

* It contains a Clinic for the correction of typing faults.

Typing for Colleges is a lesson-planned text containing 180 lessons. Each lesson will take roughly 40 minutes, but in some lessons more than 40 minutes' work is given so that teachers can be selective.

\section{Keyboard Presentation}

Lessons 1-20 present the keyboard. After the home keys have been introduced each lesson presents 3 keys at a time and contains the following sequence of activity:

(i) warm up/revision

(ii) new reaches with drills on each new reach

(iii) consolidation

Lessons 4, 8 and 12 are basically consolidation lessons intended, in the main, for weaker students. Validation tests on the keyboard presentation in schools and with groups of students of all ages in a college of further education have shown that it can be covered in as little as 6 hours, an average speed of $23 \mathrm{wpm}$ being achieved. The speed range indicated after 12 lessons was $13 \mathrm{wpm}$ to 49 wpm.

Each keyboard lesson contains more work than is required for a lesson and it is expected that the lecturer will be selective. Students might be expected to type a total of 45 lines rather than 45 new lines. In Lesson 1, for example, the lecturer might decide to omit the first 8 lines.

There is ample scope for the lecturer to select alternative approaches - word building or word repetition. It is suggested that each new reach should be drilled until the students can type it with the correct finger operation and without looking down. Only when the lecturer is satisfied with the way the first line is being typed should students go on to other lines. The lecturer will decide which of the other lines should be typed. 


\section{Skill Building and Technique Development}

From Lesson 21, the lessons are organised in a pattern which is repeated throughout the book, in units of 5 lessons. In each unit:

The first lesson is designed to develop typing technique and build speed and accuracy. It usually starts with a warm-up alphabet sentence and continues with Increase Speed passages and Improve Accuracy passages. The Increase Speed passages are all below SI 1.10 and contain literary material while the Improve Accuracy passages are written on typing or commercial topics. All passages have been written with a justified right-hand margin because research has indicated that such a margin enables students to 'boost' their typing speed by up to 5 words a minute.

The second lesson introduces a point of theory or technique. The theory is fully programmed and detailed instructions are given for its application.

A feature of this lesson is the 'framework'. Pupils copy an outline of a letter or document and write or type in the instructions. They can then refer to this for the remainder of the lesson before filing it for future reference.

The third lesson adds to the teaching of the previous lesson and provides further practice on it. Sometimes a second topic is introduced.

The fourth lesson usually begins with a warm-up alphabet sentence and continues with a Test your Skill exercise. This should be carefully marked by both pupil and teacher and repeated errors corrected by means of the remedial drills suggested in the Clinic Index on page vii. A feature of these lessons is a practical theory test covering all theory topics in a new and practical manner or the introduction of some finer theory points. The lesson concludes with elements of the Clinic.

The fifth lesson is a general consolidation lesson in which the theory for the week and previous weeks are tested in a systematic fashion. All the exercises have suggested Target times.

\section{Consolidation}

Every fifth unit in the book is a Consolidation unit which reinforces and revises all work covered to date. In Consolidation units the sequence of lessons is as follows:

The first lesson includes a warm up and Increase Speed and Improve Accuracy passages.

The second and third lessons include production work.

The fourth lesson begins with a warm-up alphabet sentence, continues with a Test your Skill and theory testing/teaching exercise before concluding with elements of the Clinic.

The fifth lesson introduces a typing topic, for example, duplicating, audio-conversion and marking techniques, to name but three.

Thus the book provides a co-ordinated course of skill building, technique development and applied typing, which is reinforced by a regular pattern of consolidation lessons and units. The theory is carefully taught and the student encouraged to think for herself in a wide variety of exercises. Where alternative styles of presentation or marking are known to be in common use they are mentioned.

\section{Acknowledgements}

The author wishes to thank the following for their help in connection with this book:

Miss Crisp of Heath Park Comprehensive School, Wolverhampton.

Students at Wulfrun College, Wolverhampton.

Mrs Bibilo of Boldmere School, Sutton Coldfield.

Pupils at T P Riley School, Bloxwich.

Mr Roger Summers for providing original documents on which many of the exercises in the book are based.

All those who have contributed handwriting samples for the manuscript exercises.

Sue Hartley, his editor, without whose help and encouragement the book would never have been finished.

All those who have assisted in so many ways - particularly with helpful criticism.

The author will be pleased to receive comments, criticisms, or queries about passages in the text. Please write to Paul Bailey, c/o John Owens, Higher and Further Education Division, The Macmillan Press Ltd, Houndmills, Basingstoke, Hampshire, RG21 2XS, United Kingdom. 


\section{Index}

Increase Speed

\begin{tabular}{|c|c|c|}
\hline wpm & $\min$ & SI \\
\hline 15 & 1 & $\begin{array}{l}1.00 \\
1.00 \\
1.06\end{array}$ \\
\hline 15 & 1 & $\begin{array}{l}1.00 \\
1.00 \\
1.06\end{array}$ \\
\hline 20 & 1 & $\begin{array}{l}1.00 \\
1.05 \\
1.05 \\
1.05 \\
1.05 \\
1.10\end{array}$ \\
\hline 25 & 1 & $\begin{array}{l}1.00 \\
1.00 \\
1.04 \\
1.04 \\
1.12 \\
1.12\end{array}$ \\
\hline 30 & 1 & $\begin{array}{l}1.00 \\
1.00 \\
1.03 \\
1.03 \\
1.03\end{array}$ \\
\hline 35 & 1 & $\begin{array}{l}1.00 \\
1.03 \\
1.03 \\
1.05\end{array}$ \\
\hline 40 & 1 & $\begin{array}{l}1.00 \\
1.02 \\
1.02 \\
1.05\end{array}$ \\
\hline 20 & 2 & $\begin{array}{l}1.00 \\
1.02 \\
1.05 \\
1.05\end{array}$ \\
\hline 25 & 2 & $\begin{array}{l}1.00 \\
1.04 \\
1.04\end{array}$ \\
\hline 30 & 2 & $\begin{array}{l}1.00 \\
1.01 \\
1.01\end{array}$ \\
\hline 35 & 2 & $\begin{array}{l}1.03 \\
1.05\end{array}$ \\
\hline 40 & 2 & $\begin{array}{l}1.02 \\
1.05\end{array}$ \\
\hline 20 & 3 & $\begin{array}{l}1.00 \\
1.03 \\
1.03\end{array}$ \\
\hline 25 & 3 & $\begin{array}{l}1.00 \\
1.01 \\
1.02\end{array}$ \\
\hline 30 & 3 & $\begin{array}{l}1.00 \\
1.01\end{array}$ \\
\hline 35 & 3 & $\begin{array}{l}1.01 \\
1.02\end{array}$ \\
\hline 40 & 3 & $\begin{array}{l}1.00 \\
1.00\end{array}$ \\
\hline 20 & 4 & $\begin{array}{l}1.00 \\
1.02 \\
1.03\end{array}$ \\
\hline 25 & 4 & $\begin{array}{l}1.01 \\
1.01\end{array}$ \\
\hline 30 & 4 & $\begin{array}{l}1.00 \\
1.01\end{array}$ \\
\hline $\begin{array}{l}35 \\
40 \\
20\end{array}$ & $\begin{array}{l}4 \\
4 \\
5\end{array}$ & $\begin{array}{l}1.06 \\
1.00 \\
1.00 \\
1.03\end{array}$ \\
\hline 25 & 5 & $\begin{array}{l}1.02 \\
1.04\end{array}$ \\
\hline $\begin{array}{l}30 \\
35 \\
40\end{array}$ & $\begin{array}{l}5 \\
5 \\
5\end{array}$ & $\begin{array}{l}1.00 \\
1.03 \\
1.06\end{array}$ \\
\hline
\end{tabular}

a

A key 1

Revision 4, 31

A4 paper 4, 39

A5 paper 4,39
A6 paper 39,160

A6 paper 39, 160

General 73

Manuscript 51,73

Postal 95

Accents

Acute, Cedilla, Circumflex, Diaeresis, Grave, Tilde, Umlaut 110

Accuracy, Improve 19

Addressee 23, 24, 85

Agenda 174, 176

Alignment scale viii

Alphabetical order 62

Ampersand key 20

Apostrophe key 16

Appointments itinerary 169

Audio-typing 148

b

C key 7

Revision 8,31

Capitals, Spaced 26

Corbon paper 173

The storage of 87

Carbon work 50

Care of the typewriter ix

Carriage viii

release levers viii

return lever vii

Contring

Horizontal 20

Vertical 41, 61

Chair, Typing ix

183

Chemical equations 81

Clinic, The vii, 19

Clinic Index vil

Claret 55

colon key 11

Combination characters Square bracket 80

Comma key 10

Composition of letters 48

Correcting aids 50

Correcting aids 50 $95,96,178,181,183$

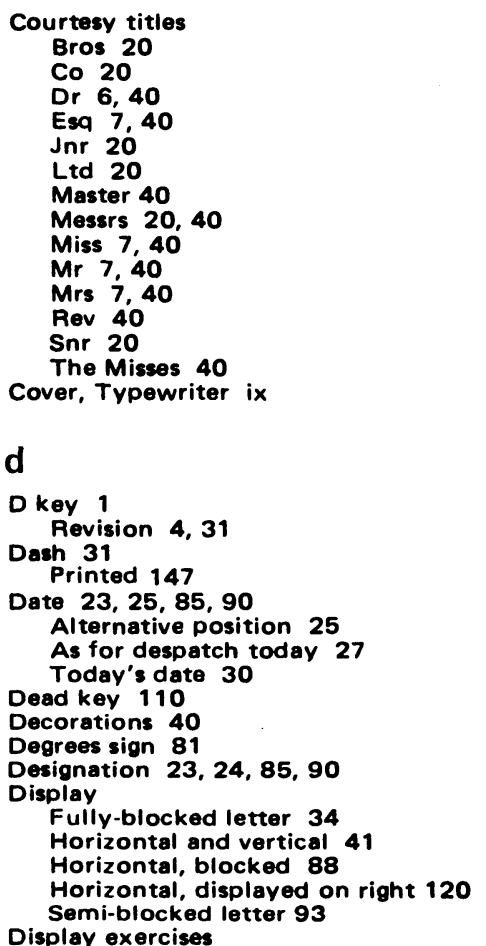
$120,146,161,171$

Typed 41, 63, 70, 88, 146

Distance from the machine ix

Division of words 16

Dotted line, Typing above 115

Duplicating

Carbon, Heat transfer, Offset litho,

C4, C5, C6 and C5/ 6 envelopes 39 ,

81

Asterisk, Brace, Dagger, Division, Dollar, Double dagger, Exclemation mark, Equals, Minus, Multiplication, Plus, Section,

Complimentary close $23,24,85,90$

Manuscript exercises $56,58,63$,

Typed exercises 56, 58, 70, 78 $88,96,106$ Spirit, Stencil 173

e

E key 2

Revision 4, 36

Electric typewriters 122

Cleaning 122

Moving 122

Typing mat for 122

Elite type 4

Enclosures, Letters with 25

Encs 25

Envelopes

Addressing 40

Confidential 40

POP size 40

Practice 42, 43

Private 40

Sizes (C4, C5, C6, C5/6) 39, 40

Equations, Chemical 81

Eraser, Use of 50

Errors

Common typing 52

Correction of 92, 142

Examination papers, The marking of 98

f

F key 1

Revision 4, 42

Farenheit 81

Feet 81

Figures

$0: 13,1: 13,2: 17,3: 15,4: 13,5: 13$ $3,1: 13,2: 17,3: 15,4: 13$
$6: 13,7: 13,8: 15,9: 17$
Typing in columns 34

Use of words and 18

Fingers ix

Footnotes 80

Typing of 144

For the attention of

Envelopes 40

Fully-blocked letters, open punctuation 29

Fully-blocked letters, punctuated

Semi-blocked letters 91

Foreign languages

French 110, 121

German 167

Welsh 110

Form letters 116

Forms 115

Deletion 141

Filling in 115

Invoice 130

Order 125

Statement of Account 135

Telephone Message 140

Fractions 31

Full stop 5, 55

Fully-blocked letter layout

Open punctuation 23

Punctuated 85

G key 5

Revision 8,42

Guide, Paper viii

H key 2

Revision 4, 47

Half-space corrections 92, 142 Halfpenny 18

Hands ix

Hanging paragraphs 17,105

Headed sheet 23

Headings 105

Main 105

Over columns 65, 68, 71

Paragraph 105

Shoulder

Underlining 61

Heat transfer duplicating 173

Home keys ix, 1

Hon Sec 141

Horizontal centring 20

Horizontal display 41

in columns 60

Hyphen key 14

i

I key 3

Revision 4, 52

Imperial measurement 76

Improve Accuracy 19

Inches 81

Increase Speed 14

Indented paragraphs 15, 105

inferior characters 81

Insetting 132

Inside address 24,85

Interliner viii, 97

Invoices 130, 131, 133, 145

Initials, Punctuation of 6,85

Itinerary

Appointments 169, 171

Travel 170, 171

j

key 1

Revision 4,57 


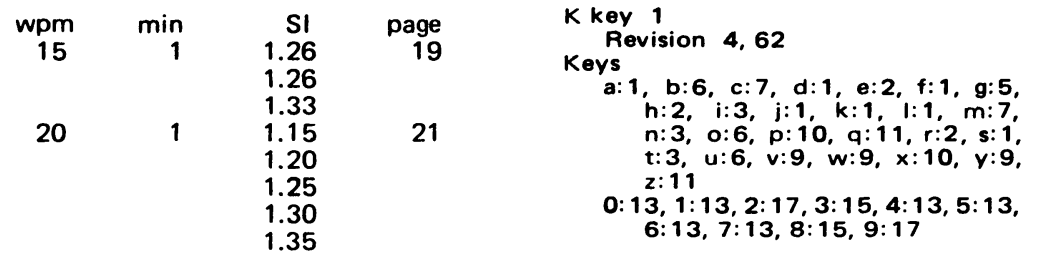

k

$6: 13,7: 13,8: 15,9: 17$

I

L key 1

Revision 4,67

Leader dots 75

Letters

Composition of 48

Display 34, 93

Enclosures, with 25, 91

Examples 22

For the attention of 29, 91

Framework

Fully-blocked, open punctuation 23

Fully-blocked, punctuated 85 Semi-blocked 90

Personal 165, 166

Personal business 164, 166

Subject heading, with 30,91

Subject heading, with
Suitable margins 27

Telephone numbers 164

Letters, Exercises

Corrections, with 58, 63, 78, 95

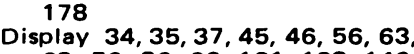
$68,76,86,93,121,138,146$, $153,158,163,168,178$

Enclosures, with 25, 27, 29, 30 $37,45,53,56,86,88,91,121$, $157,158,163,178$

For the attention of $29,32,34$, $35,37,45,46,53,68,78,88$, $91,95,96,121$

Form 116 and $118,138,141$ and 143, 151

Manuscript 27, 30, 32, 35, 37 $70,76,78,88,95,96,121$ $138,146,151,153,157,158$ $163,166,168,178$

Personal 164, 165, 166

Subject heading, with $30,32,35$, $37,43,45,46,63,68,70,76$ $78,88,91,96,121,138,141$. 157,158

Typed $23,24,25,27,29,30,32$, $34,35,37,45,46,86,90,91$. $93,116,141,164,165,166$

Left shift key 7

Line-end division of words 16

Line-space regulator viii

Line-sp

of type ix, 4
itho, Offset 173

m

M key 7

Revision 8, 67

Manuscript abbreviations 51, 73

Manuscript exercises 16, 50, 51, 53 . 108,175

Margin release 16

Margins vii

Suitable for letters 27

Typing line with equal 51

Mat, Typing 13

Meetings, Terms used at 73

Memoranda 159, 161, 172

Metric symbols and abbreviations

ampere, candela, candela per $43,45,46,53,56,58,63,68$.

Spacing of vii cubic millimetre, decible degree Celsius (reading and difference), gramme, joule. kilogramme, kilometre, kilowatt, litre, megawatt, metre, millimetre newton second, square kilometre, square metre, tonne, volt. watt 111

\section{Minutes 179,181}

Money

in columns 100, 101 exercises 100,101, 103

Monochrome ribbon 8

Moving typewriters 122

n

N key 3

Revision 4, 72

Numbers

$0: 13,1: 13,2: 17,3: 15,4: 13,5: 13$

6:13, 7:13, 8:15, 9:17

Practice 36

Punctuation 26

Numerals, Roman 17, 81

Numerical order 71

\section{o}

O key 6

Revision 8, 72

Offset litho duplicating 173

Open punctuation $8,24,86$

Letter layout 23, 24

Orders 125, 126, 128, 145

Ounces 76

p

P key 10
Revision 12, 77
p.m. 14

p.p. 15

Paper:

bank 12

grades 12

guide viii

release lever viii

sizes 4

Typing 12

Paper and envelope sizes 39, 40

Paragraph headings 105

Paragraphs

Blocked 15, 105

Blocked, in double-line spacing 117

Hanging 17, 105

Indented 15, 105

Pence 18

Percentage key 26

Personal letters 165

Personal business letters 164

Pice type 4

Platen viii

knobs viii

release lever viii

Poetry 123, 127, 162

POP envelopes 40

Post Office abbreviations 95

Post Office Guide 40, 123

Postal abbreviations

Avenue, Bank, Chambers, Close, Cottage, Court, Crescent, Cross, Drive, Estate, Farm, Gardens, Great, Green, Grove, Heath, Hill, House, Lane, Little, Lodge, North, Park, Rise, Road, Row North, Park, Rise, Road, Row, Square, Street, Terrace, Upper,
View, Walk, Way, West, Wood View

Postal town 24, 40

Postcards 160, 161, 172

Postcode 23, 24, 40

Pound sign

\& 16
Printers' correction sians

Caps, Claret, Close up, Dash, De lete, Full stop, Comma, Hyphen, Ic, New paragraph, Quotation marks, Run on, Space, Stet, Straighten margin, Straighten text, Transpose, uc 55

Printing point indicator viii

Private 40

Punctuation

Abbreviations 6, 7, 85

Ampersand 20

Apostrophe 16

Brackets ( ) 18

Colon 11

Comma 10
Dash 31

Decorations 40

Envelopes 40

Feet 81

Fractions 31

Full stop 5

Initials 6

Inches 81

Numbers 26

Open 8

Percentages 26

Pound $(E)$ sign 16

Pounds and ounces 76

Practice 36

Qualifications 40

Question mark 14

Quotation marks 17

Semi-colon 1

Solidus 20

q

Q key 11

Revision 12, 77

Qualifications 40

Question mark key 14

Quick test exercises 26, 31, 36, 42. 47, 52, 57, 67, 72, 77, 82, 87 $92,97,106,112,117,121,127$. $132,137,147,152,157,162$, 167,168

Quotation marks 18

R key 2

Bevision 4,82

Ratchet release lever viii

Ready-to-type position ix

Record ribbon 8

Reference 23, 29, 85

Books of 123

Reports 175, 183

Ribbon Indicator ix

Ribbons, Typing

Monochrome 8

Record 8

Right shift key 5

Roller viii

Roman numerals 17,81

Ruled tabulation 149,156

with column headings 154,155

Ruling up of tabulations 149,150

$\mathbf{S}$

S key 1

Revision 4, 82

Salutation 23, 24, 85

Semi-blocked letter layout 90

Semi-colon key 1

Shift keys ix

Left 7

Right 5
19

Shoulder headings 105

SI System 111

Signatory 23, 24, 90

Signature per procurationem 151

Sitting position ix 


\begin{tabular}{|c|c|c|c|}
\hline \multicolumn{4}{|c|}{ Test your Skill } \\
\hline $\min$ & words & SI & page \\
\hline 1 & $\begin{array}{l}26 \\
29 \\
37 \\
42 \\
49 \\
52\end{array}$ & $\begin{array}{l}1.15 \\
1.31 \\
1.32 \\
1.24 \\
1.25 \\
1.46\end{array}$ & $\begin{array}{l}19 \\
26 \\
31 \\
36 \\
42 \\
47\end{array}$ \\
\hline 2 & $\begin{array}{l}55 \\
62 \\
79 \\
80 \\
97\end{array}$ & $\begin{array}{l}1.30 \\
1.15 \\
1.28 \\
1.25 \\
1.30\end{array}$ & $\begin{array}{l}52 \\
57 \\
62 \\
67 \\
72\end{array}$ \\
\hline 3 & $\begin{array}{r}93 \\
94 \\
105 \\
120 \\
151\end{array}$ & $\begin{array}{l}1.31 \\
1.29 \\
1.29 \\
1.27 \\
1.31\end{array}$ & $\begin{array}{l}77 \\
82 \\
87 \\
92 \\
97\end{array}$ \\
\hline 4 & $\begin{array}{l}103 \\
127 \\
154 \\
171 \\
179\end{array}$ & $\begin{array}{l}1.37 \\
1.27 \\
1.31 \\
1.30 \\
1.42\end{array}$ & $\begin{array}{l}102 \\
107 \\
112 \\
117 \\
122\end{array}$ \\
\hline 5 & $\begin{array}{l}146 \\
159 \\
177 \\
210\end{array}$ & $\begin{array}{l}1.30 \\
1.22 \\
1.28 \\
1.48\end{array}$ & $\begin{array}{l}127 \\
132 \\
137 \\
142\end{array}$ \\
\hline 10 & $\begin{array}{l}251 \\
260 \\
260 \\
270 \\
279 \\
316 \\
471 \\
482\end{array}$ & $\begin{array}{l}1.38 \\
1.37 \\
1.47 \\
1.31 \\
1.31 \\
1.24 \\
1.35 \\
1.18\end{array}$ & $\begin{array}{l}147 \\
152 \\
157 \\
162 \\
167 \\
172 \\
177 \\
182\end{array}$ \\
\hline
\end{tabular}

Skill, Test your 19

Solidus key 20

Space bar ix

Spaced capitals 26

Spacing, Types of viii

Specification 152, 168

Speech 47, 137

Speed, Increase 14

Spirit duplicating 173

Spreading 142

Squeezing 92

Statement of Account 135, 136, 138 ,$$
145
$$

Stencil duplicating 173

Sub-title 105

Subject heading

Fully-blocked letters, open punctuation 31

punctuated 86
Semi-blocked letters 91

Subscription 24

Sums of money in context 18

Superior characters 81

Syllabic intensity 14

$\mathbf{t}$

T key 3

Revision 4, 87

Tabulation

Boxed ruled 149, 156

Boxed ruled with column headings 154,155

Headings 61

Headings over columns $65,68,71$

Horizontal 60

Ruling up 149, 150

Vertical 61

Tabulation exercises

Alphabetical order $62,63,66,68$, $72,83,102,113,128,153$,

Column headings $65,66,68,71$,
$76,83,102,103,118,128$,
$133,154,155,156,158,163$ 176,180

Leader dots

$75,76,102,103$,

133,180

Manuscript 60, 61, 62, 63, 66,

$68,71,72,76,83,102,103$

$113,118,128,133,153,154$

$165,156,158,163,176,180$

Numerical order 71

Ruled 149, 150, 153, 154, 155

$156,158,163,180$

Typed 60, 61, 65, 66, 68, 76 $149,150,154,155,156,180$

Tabulator, The 20

Tabulator bar ix

Target times 25

Technical abbreviations

bhp, cc, hp, ohv, rpm 152

Technique ix

Telephone message forms 140, 143 145

Test your Skill 19

Time

am and pm 14$$
\text { tle } 105
$$

Touch control lever ix

Touch control

Travel itinerary

Typewriter, Parts of

alignment scale, bail bar, bail bar rollers, carriage, carriage release levers, carriage return lever, interliner, line space re gulator, margins, paper guide, paper release lever, platen. platen knobs, platen releaso lever, printing point indicator. ratchet release lever, roller vin trol lever ix

Typewriter, The vili

Typing errors 52

Typing lines with equal margins 51

ping mat 13

Electric typewriters 122
Typing paper 12

Typing ribbons 8

Typing word vii

Twenty four hour clock 17

$\mathbf{u}$

U key 6

Revision 8, 87

Underscore key 9

Underscored line, Typing above 115

v

$\checkmark$ key 9

Revision 12, 92

Vertical display 41

in columns 61

w

W key 9

Revision 12, 97

Window envelopes 24

Words, Line-end division of 16

Words and figures, Use of 18

$\mathbf{X}$

$X$ key 10

Revision 12, 102

Y

$Y$ key 9

Revision 12, 102

Years, Typing of 26

$\mathbf{z}$

Z key 11

Revision 12, 107 


\section{The Clinic}

All typists make errors, but the good typist finds out why she makes them and corrects her faults rather than waste her time erasing the same error many times. Keep a record of your typing progress as you type the Test your Skill exercises and, each week, make a note of your mistakes and correct those you repeat by using the drills suggested below. You can easily work out your typing speed by dividing the number of words you have typed by the number of minutes you have spent typing them. In typing, five strokes count as a word, a space being counted as a stroke.

There are many causes of typing faults, the most common being lack of concentration and poor technique. The typist should always be relaxed, feet firmly on the floor and body leaning slightly forwards. When typing, only the fingers should move and any movement of wrists, forearms and body is a sign of poor technique. Get others to watch while you are typing to see if you have this basic fault.

The index below lists the most common faults. Look up your fault and type the suggested corrective exercise(s) 3 times - once for practice, once for speed and once for accuracy.

ALPHABET KEYS If you hesitate, or type individual letters incorrectly, type one of the following remedial drills:

$\begin{array}{ll}\text { A } & 4,31 \\ \text { B } & 8,31 \\ \text { C } & 8,31 \\ \text { D } & 4,31\end{array}$

$\begin{array}{ll}\text { E } & 4,36 \\ \text { F } & 4,42 \\ \text { G } & 8,42 \\ \text { H } & 4,47\end{array}$

$\begin{array}{ll}\text { I } & 4,52 \\ \text { J } & 4,57 \\ \text { K } & 4,62\end{array}$

4,52

$\begin{array}{ll}M & 8,67 \\ N & 4,72 \\ O & 8,72\end{array}$

4,67

8,72
12,77

$\begin{array}{rr}\text { Q } & 12,77 \\ R & 4,82 \\ S & 4,82 \\ T & 4,87\end{array}$
2,77
4,82
4,87

$U$
$W$
$X$

8,87
12,92
12,97
12,102

Y 12,102

$\mathrm{Z} \quad 12,107$

NUMBERS If you hesitate or look down when typing numbers type the following drills:

$\begin{array}{lrll}\text { 1. } & 13,17 & 4 . & 15,17,127 \\ 2 . & 122, & 5 . & 15,17,127 \\ 3 . & 17,122 & 6 . & 15,17,127\end{array}$

7. $15,17,127$
8. 17,122
9. 122

0. 13

'MUDDY' TYPING If your typing is 'muddy' and not clean cut, tap the keys sharply as you type and listen for the tap of the keys as they hit the paper. Type the drills on pages 142 and 172.

SPACING BETWEEN WORDS If you have difficulty with the spacing between words bounce your right thumb off the space bar (your fingers should not move as you hit the space bar) as you type the drills on pages $2,3,5,7,9,10,11,147$.

CAPITAL LETTERS If you have difficulty when typing capital letters, stab the shift key down with the little finger of the hand not typing the letter as you type the following:
Left shift key
8, 112;
right shift key
8, 117;
both shift keys
12.

REPEATED LETTERS If the second of repeated letters in words causes you to slow down or make mistakes, type the second letter slightly harder than the first as you type the exercise on page 142.

POOR LEFT MARGIN If the left-hand margin is uneven, return the carriage smartly at the end of each line without moving the right hand from the home keys as you type the exercises on pages 36 and 177.

PUNCTUATION If you have difficulty with punctuation type the exercises on pages 8, 12 and 36 .

TABULATOR BAR If you cannot operate the tabulator bar efficiently, try the drill on page 132. Hold the tabulator bar down until the carriage stops moving. Try to type the drill in a half-minute.

COMBINATION CHARACTERS If you have difficulty with combination characters, type the drills on page 137.

CONCENTRATION If you suffer from poor concentration, type the drill on page 177 or the foreign language passages on pages $110,121,167$.

LETTER COMBINATIONS If you have difficulty with certain letter combinations, make up a line of words containing the letter combination causing difficulty and type it 3 times. For example if the combination 'en' was causing difficulty use words such as: student tent dent - and so on. Some drills are suggested for the following: 'le' words page 132; 'an' words page 137: 'ei' words page 157.

STRENGTHEN YOUR HANDS To strengthen your hands ask your teacher for some hand exercises such as gripping and stretching. To strengthen the left hand try the drill on page 162 and to strengthen the right hand the drill on page 167.

TO IMPROVE SPEED To improve your typing speed, practise regularly and in particular the Increase Speed passages given each week. The following drills should al so assist:

Alternate hand drills pages 142 and 172; Common phrases page 152.

ALPHABET SENTENCES In each Skill lesson, warm up by typing an alphabet sentence. You will find them on pages 14, 21, 26, 28, 31, 33, $36,38,42,44,47,49,52,54,57,59,62,64,67,69,72,74,77,79,82,84,87,89,92,94,97,99,102,104,107,112,114,117,122,124$, $127,132,134,137,142,144,147$. 


\section{The typewriter}

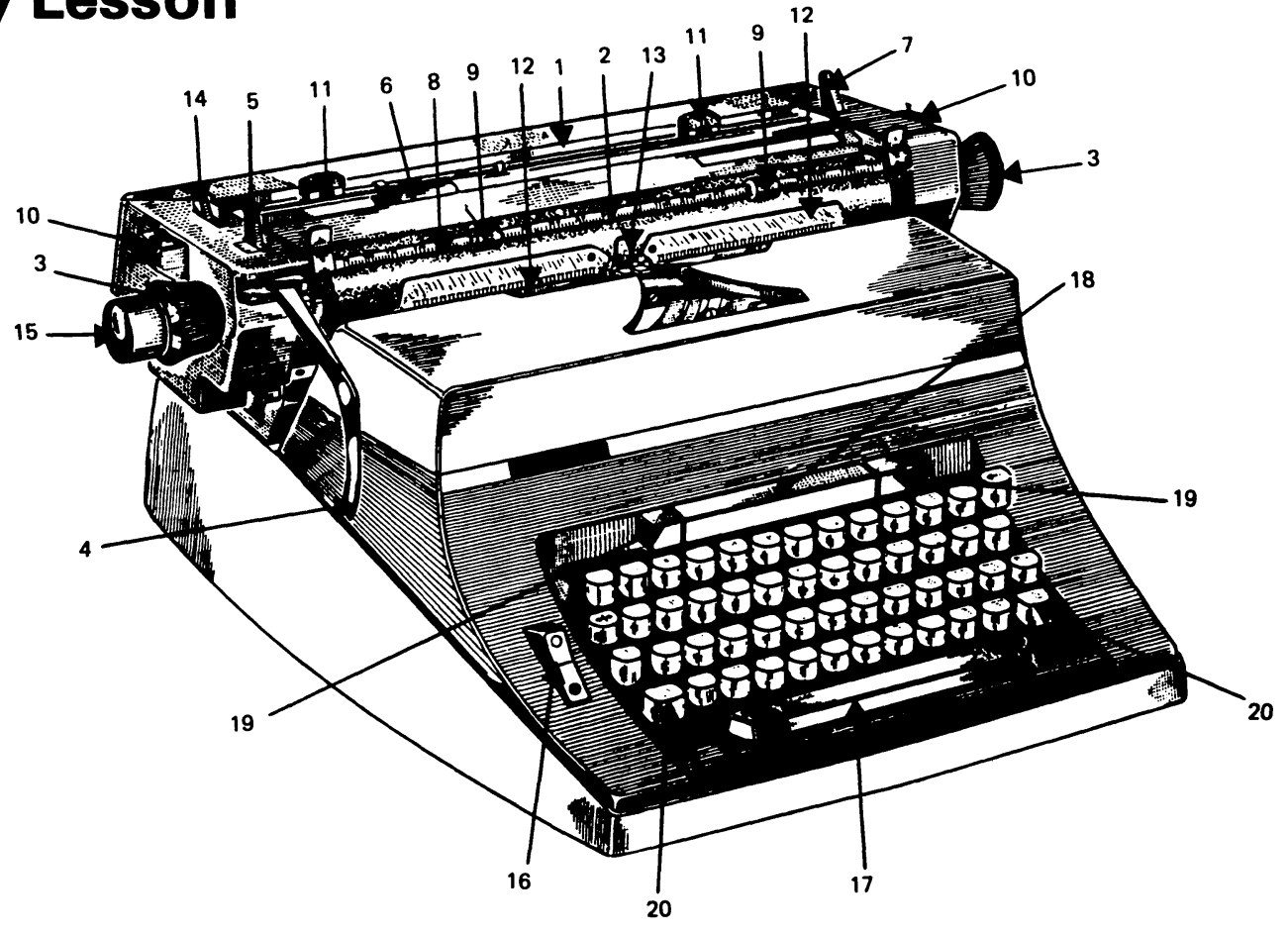

Before starting to type Lesson 1 you must learn the names and functions of the parts of the typewriter. Follow your teacher's guidance or use the manual for your typewriter to identify the various parts. The diagram will assist you. The moving part of the machine is the carriage (1). Mounted in the carriage is the roller (2) or platen, which is a piece of wood covered with rubber. The purpose of the platen is to hold the paper and enable the typist to move it up or down as required, using the platen knobs (3) or the carriage return lever (4). The platen turns each time you return the carriage, using the carriage return lever, the amount of movement being determined by the setting of the line space regulator (5). The setting of the line space regulator varies from machine to machine but you must learn the difference between single, lineand-a-half and double-line spacing.

$\begin{array}{ll}\text { This is a sample of work } & \text { This is a sample of work } \\ \text { typed in single-line } & \text { typed in line-and-a-half } \\ \text { spacing. } & \text { spacing. }\end{array}$

\section{This is a sample of work}

\section{typed in double-line}

$$
\text { spacing. }
$$

The paper guide (6) allows you to insert paper at the same point accurately each time. To straighten the paper use the paper release lever (7). This releases the rollers holding the paper on to the platen so that you can move the paper from side to side, straighten or remove it. The bail bar (8) and the bail bar rollers (9) hold the paper on to the front of the platen; the bail bar must be raised or released when you remove or insert the paper. Since the bail bar is calibrated the point reached on the paper can be determined. The calibration varies, most machines being numbered from 0 on the left.

So that the carriage can be moved freely from side to side for positioning purposes, 2 carriage release levers (10) are fitted. These disengage the carriage drive mechanism.

Margins can be positioned by means of movable margin stops (11), the operation of which varies with different makes of machine.

In front of the carriage, an alignment scale (12) is fitted. This scale, often in single-space divisions, is used to show the exact line along which the typing is done. In the centre of the scale is the printing point indicator (13), which shows the point at which the machine will next print. The printing point indicator sometimes serves as a card holder.

The platen release lever (or ratchet release lever) (14) enables you to make fine adjustments to the platen as for example when typing above ruled lines. When this lever is pulled forward the gear determining the line spacing is disengaged but when it is released the gear falls back into mesh. The interliner (15) is used to make fine adjustments to the platen of a permanent nature and is engaged by pushing the centre of the left-hand platen knob. Its release is automatic. 
On the body of the machine is the ribbon indicator (16), which is used to select different ribbon positions for black, red or stencil typing. The space bar (17) is depressed to move the carriage by one letter-space. Some machines have adjustments to enable more than one space to be advanced at a time. The tabulator bar (18) enables you to find predetermined points along the typing scale and 2 keys (19) are used in conjunction with it - one sets tabulator stops while the other clears them either singly or together.

Most modern machines have a touch control lever which makes the keys harder or lighter to depress - and thus type. There are slight variations in the size of typewriter keyboards, and if you have large hands you should try to find one of the bigger keyboards. Good matching of your hands to the keyboard is important to the correct operation of the shift keys (20). Once you have found a machine that seems to be the right size you should on no account change it or 'swop' with someone else, at least for the first term.

\section{The 'ready-to-type' position}

Before you can type properly, you must make sure that you are sitting correctly. Since people vary in shape and size, typing chairs are made so that they can be adjusted to suit your particular needs. Make sure you check that your chair is correctly adjusted before you start to type. The correct typing position is as follows:

\section{Feet}

The height of the chair should be adjusted so that your feet are flat on the floor and your thighs are parallel to the floor. Keep your feet slightly apart, braced firmly on the floor.

\section{Body}

Your body should be relaxed, with the backrest of the chair adjusted so that it supports you in the small of your back and not your shoulders. Set the backrest so that you are leaning slightly forwards. You should never try to type leaning backwards.

Sit so that you are one hand-span from the front edge of the typewriter, which should itself be parallel to the edge of your desk. It is very important that you are the right distance from the machine, so check this point every time you sit down to type.

\section{Fingers}

Your arms and elbows should hang loosely. Make sure that your finger-nails are not so long that they get in the way of the keys. Your fingers should be bent so that only the tips touch the keys, while your hands should be at an angle of roughly $45^{\circ}$ to the typewriter. The palms of your hands must be clear of the machine, and the space bar in particular.

\section{Technique}

Now that you are sitting correctly you should practise putting the paper into the typewriter. Use a backing sheet to protect the rubber surface of the platen. Make sure that the paper is held between the first finger and thumb of the left hand against the paper guide at 0 on the bail bar scale on the left, and that only the right hand sharply turns the platen knob to bring the paper into the machine. Use the paper release lever to make any adjustments.

You should leave a space of about $25 \mathrm{~mm}(1 \mathrm{inch})$ at the top of the page. This is done by using the carriage return lever to turn up 7 single lines from the top edge of the paper. Practise returning the carriage. Move the lever, using the side of your left fore-finger only. Never grip the return lever. You teacher will show you the correct 'ready-to-type' position, and how to place your hands on the 'home keys', with the left hand covering asdf, and the right hand covering; ;kj. Practise bouncing your right thumb off the space bar as you keep your fingers in position over the 'home keys', as demonstrated by your teacher.

When you have finished your lesson, take the paper out of the machine, using the paper release lever, centre the carriage and lock it by bringing the margins together. Do not forget to put the cover, which should be kept over the back of your typing chair when you are typing, on the typewriter when you are not using it. If you neglect this, the machine will eventually become choked with dust and the ribbon will dry out. Look after your typewriter. 